\title{
Governance Conditions for Improving Quality Drinking Water Resources: the Need for Enhancing Connectivity
}

\author{
Susanne Wuijts ${ }^{1,2}$ (D) Peter P. J. Driessen ${ }^{2}$. \\ Helena F. M. W. Van Rijswick ${ }^{3}$
}

Received: 27 May 2017 / Accepted: 20 November 2017 /

Published online: 3 December 2017

(C) The Author(s) 2017. This article is an open access publication

\begin{abstract}
Realising the water quality objectives of the European Water Framework Directive have appeared to stagnate over the last decade all across Europe because of their highly complex nature. In literature, governance approaches tend to be regarded as the best way of dealing with complex water issues, but so far little empirical evidence has been reported on this perspective in regard to water quality issues and thus identifying relevant interventions for both policy makers and other stakeholders. In this paper we have analysed how conditions of governance contribute to the realisation of water quality objectives at different types of drinking water resources in the Netherlands. The water quality challenges at these resources, nitrates, pesticides, industrial chemicals and pharmaceuticals, can be recognized in other European countries as well. The analysis demonstrates the importance to enhance connectivity between institutional levels and upstream regions based upon the characteristics of the water system and driving forces for water quality and thus involve the actors that have the authority and the means to take effective measures. The two other important conditions of governance approaches for water quality improvement which were identified are the use of joint factfinding to gain a shared perception of risks, and the use of explicit decision-making and close monitoring of outcomes (re. water quality improvement).
\end{abstract}

Keywords Conditions of water governance - Water quality objectives · Drinking water resources · Cross-scale connectivity · Water Framework Directive $\cdot$ Science-policy interactions

Electronic supplementary material The online version of this article (https://doi.org/10.1007/s11269-0171867-3) contains supplementary material, which is available to authorized users.

Susanne Wuijts

susanne.wuijts@rivm.nl

1 National Institute for Public Health and the Environment (RIVM), PO Box 1, NL-3720 BABilthoven, the Netherlands

2 Copernicus Institute of Sustainable Development, Utrecht University, Utrecht, the Netherlands

3 Utrecht Centre for Water, Oceans and Sustainability Law, Utrecht University, Utrecht, the Netherlands 


\section{Introduction}

Worldwide, the access to safe drinking water has improved in the last decade from $76 \%$ of the world's population to $91 \%$ in 2015 (WHO 2016). However, restoring and preserving the quality of drinking water resources is still a challenge (Salinas 2015). WHO conclude that at least 1.8 billion people worldwide use a drinking-water source that is contaminated with faecal matter (2016).

In Europe, the preservation of good quality drinking water resources is on the European and national policy agendas of Member States (MS). In the 1990s, a substantial improvement was observed (e.g. (Dalhuisen et al. 2003)), thereafter, the improvement of the water quality of surface water and groundwater systems has seemed to stagnate in many MS (EC 2013). At the same time, new and, as yet, unregulated water quality issues emerged, like the presence of pharmaceuticals and micro-plastics which has initiated discussion on how these issues could be addressed (Brack et al. 2015; Houtman 2010; Metz and Ingold 2014; Ter Laak et al. 2010; Van der Aa et al. 2013).

Drinking water resources are located within river basins that often serve multiple other water users such as agriculture, industry, shipping and nature preservation. Point sources like sewage effluent and diffuse pollution from agricultural areas and run-off from roads, may threaten water quality. In addition, the hydrological system itself is complex and subject to multiple regulatory frameworks, all of which add to the complexity of addressing water quality issues.

The European ambitions in regard to water quality are set out in the Water Framework Directive (henceforth WFD, 2000/60/EC). The WFD contains specific elements like the integrated river basin approach, the role of stakeholders and the importance of balancing the costs and benefits of water services.

The European Commission (EC) noted that, throughout Europe, 25\% of the groundwater still suffers from poor chemical status and because of gaps in information there is some uncertainty about the chemical status of surface waters too (EC 2013). A national evaluation of drinking water resources conducted in the Netherlands showed that the water quality of over half of the drinking water resources were 'at risk' or 'possibly at risk' ${ }^{1}$ of not meeting WFD 'objectives for water intended for human consumption' (WFD, Article 7). The substances raising concern were pesticides, nitrates, substances related to historical point source soil pollution and emerging substances (Wuijts et al. 2014). Other studies demonstrated that the challenges for drinking water resources are comparable in neighbouring countries like Belgium, the United Kingdom, Germany and Denmark (e.g. (Flindt Jörgensen et al. 2016; Overheu et al., 2011; Six et al. 2015). These can also be recognised in the wider international arena (e.g. (Howard and Schmoll 2006; Kayser et al. 2015)).

Due to the stagnating water quality improvement there is much concern as to whether the WFD objectives will be met with the existing policy plans (EC 2013; OECD 2014). This gives rise to the question: how can this stagnation be explained and what additional actions are necessary to achieve the water quality objectives? In the Water Blueprint, the EC sets out the necessary measures to safeguard Europe's waters over the coming years, such as the improvement of water governance within river basins (2013). It is, however, unclear what specific governance conditions might result in better water quality in practice (Leventon 2015; Metz

\footnotetext{
${ }^{1}$ This means that, for one or more specific water quality parameters, a level of $75 \%$ of the standard is exceeded and this tendency could lead to non-compliance by the end of the planning period of the WFD.
} 
and Ingold 2014; Pahl-Wostl et al. 2012). Several publications address the importance of analysing the impact of governance on water quality outcome (e.g. Newig and Fritsch (2009), Blackstock et al. (2012)) but an actual effort to that end seems only been published by PahlWostl et al. (2012). This approach however, was too aggregated to identify improving conditions for specific water quality issues at a regional or local scale. According to Quevauviller (2010), one of the key points in discussions among scientists, policy-makers and actors in Europe over the last decade, has been the need for a science-policy interface related to water, in order to develop more effective conditions of governance to address water quality challenges. Policy responses should be based on a sound knowledge base of the drivers of water quality in order to be effective (Howard and Schmoll 2006; Metz and Ingold; WHO 2009).

In this study we aim to take the analysis on water quality governance a step further by specifically focusing on the effects at the local or regional scale. We will investigate the relationship between water quality objectives and the conditions of governance that contribute to the realisation of these objectives: what are these conditions according to the scientific literature, how are they applied in practice and what gaps can be identified that explain the stagnation taking place in water quality improvement? Conditions of governance are defined in this study as the elements and activities that are necessary in a governance approach to realise water quality objectives. We have analysed the conditions of governance approaches used to achieve water quality objectives in a case study: the protection of drinking water resources in the Netherlands and what lessons can be learned about the conditions of governance set in place to improve water quality that could be applied to similar challenges in other countries and river basins.

\section{Analytical Framework to Identify Governance Conditions to Address Water Quality Issues}

In the EU, the complexities affecting the realisation of water quality objectives, have become more and more apparent since the 1980s resulting in a paradigm shift. Different studies have described this transforming influence on the development of European directives (EC 2001; Howarth 2017; Lange et al. 2013; Lee 2009; Plambeck 2015; Scott and Trubek 2002; Van Holten and Van Rijswick 2014; Van Rijswick 2008). During the last decade, a government approach in which top-down regulation and hard standards prevailed, developed into a governance approach, characterised by bottom-up regulation and more qualitatively formulated objectives, leaving the standard setting to the MS themselves. The reasoning for this shift was the increasing awareness that complex water issues could not be addressed by legislation only and are specific for a river basin (Bucknall 2006; Howarth 2017; Lee 2009; OECD 2015; Orr et al. 2015). During this period, many studies on water governance were published. The scientific debate so far seems to have focused on the challenges of governance (Dieperink et al. 2012; Van Buuren and Koppenjan 2014; Van Popering-Verkerk and Van Buuren 2016), the capacities for governance (Koop and Van Leeuwen 2016), the criteria for evaluation like effectivity, efficiency and legitimacy (Adger et al. 2005; Den Uyl and Driessen 2015; Orr et al. 2015) and the conditions for good governance (Bucknall 2006; OECD 2015; Pahl-Wostl et al. 2012; Rijke et al. 2012). To date, empirical studies on how conditions of governance could contribute to improve specific water quality issues are scarce. Boeuf and Fritsch (2016) concluded that there are many publications on the preparation and implementation phase, 
yet there is little comparative research on the progress made in the first planning cycle of the WFD and thus on the effectiveness of the WFD process. This understanding however, is important to identify relevant interventions for both policy makers and other stakeholders involved.

So, although the literature seems to have not yet addressed how conditions for governance approaches could lead to better water quality in practice at a specific resource, various publications demonstrate one or more important general conditions, like the interconnective capacity of governance (Den Uyl and Driessen 2015; Edelenbos et al. 2013; Gilissen et al. 2016; Scott and Trubek 2002), the importance of indicators (OECD 2015), normative aspects (Driessen and Van Rijswick 2011) and the role of the stakeholders perception of the problems (Runhaar et al. 2006; Warner and Van Buuren 2016). Additionally, multiple publications describe frameworks to analyse conditions for governance from a broader perspective, combining technical, institutional and relational aspects (e.g. (Bressers et al. 2013; Havekes et al. 2013; OECD 2015; Pahl-Wostl et al. 2012; Rijke et al. 2012; Van Rijswick et al. 2014)).

Our proposition for this study is that to address water quality issues effectively, the governance approach should be linked up with the water system characteristics, the drivers of water quality issues and with the authorities which have the means to adopt adequate measures and monitor the progress of said measures. To test this proposition in a case study, it is important that the analytical framework offers the possibility of doing so.

We have compared four frameworks for this purpose (Havekes et al. 2013; OECD 2015; Pahl-Wostl et al. 2012; Van Rijswick et al. 2014) (see supplementary material). For the purpose of this study it is important that the framework offers the possibility of analysing how the governance approach is linked to the water system characteristics and the drivers of water quality issues. The frameworks described by Havekes et al. (2013), OECD (2015) and Pahl-Wostl et al. (2012) do not include any analyses of the measures planned or undertaken, or of the monitoring of the progress of water quality improvement. These frameworks are, therefore, less appropriate for use in the analysis in this study. The framework described by Van Rijswick et al. (2014) is the only one of these four frameworks that takes those two elements into account and, for this reason, was selected for our study. This multidisciplinary framework, with a diagnostic nature, aims to identify strengths and weaknesses in water governance approaches that need to be addressed in order to deal with water issues effectively. The ten building blocks identified are interdependent and evolve during a governance process. This cyclic element of the framework, in combination with the building blocks related to implementation, offers the possibility to assess the adaptive capacity of a governance approach in order to improve water quality. Each of the building blocks holds several questions to be answered to assess the governance approach for that element. The framework is, however, rather generic in its description of some of the different elements, especially regarding the water system characteristics. Therefore, we have used the Water Safety Plan approach (WSP) (WHO 2009) to identify relevant indicators for the characterisation of the resource, and the drivers that may influence it, in order to take adequate measures to improve the water quality. The WSP approach was initially designed as a risk assessment and risk management approach to ensure a safe and sustainable drinking water supply from the resource to the drinking water tap. With the resulting analytical framework (see Fig. 1) we tested our proposition. 


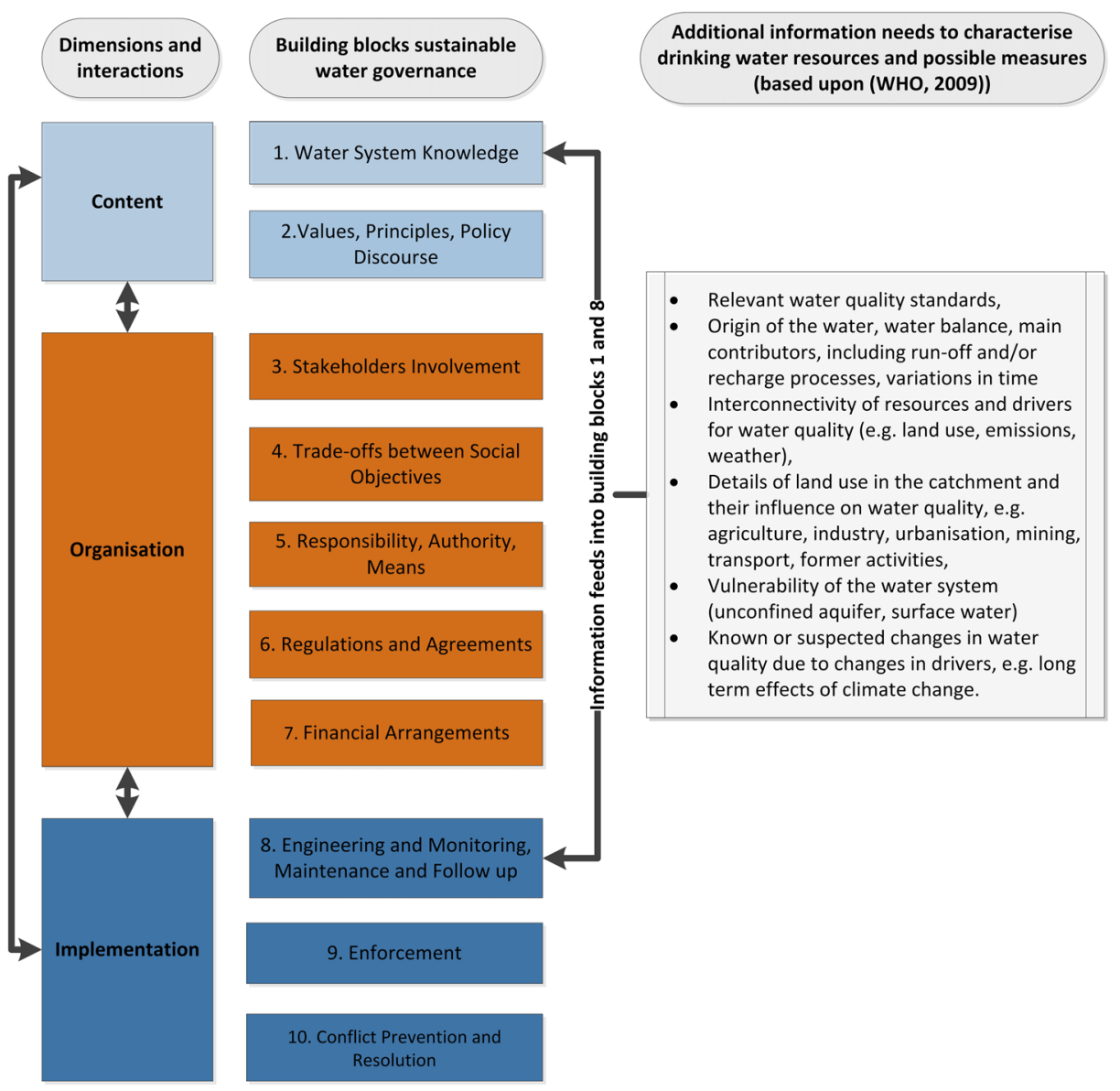

Fig. 1 Analytical framework used in this study, based on (Van Rijswick et al. 2014; WHO 2009)

\section{The Case Study: Preserving Drinking Water Resources in the Netherlands}

In this case study we analysed the conditions of governance for the protection of drinking water resources in the Netherlands in regard to their contribution to water quality improvement. We carried out an in-depth analysis of three drinking water resources. The criteria for selection of these resources were: the differences in the water system characteristics, the type of resource, the type and scale of water quality issues (regional, national and international) and the authorities and stakeholders involved. The type of resources, and the issues at stake at these resources, are common to other resources in the Netherlands (Wuijts et al. 2014) and will therefore provide data that can be generalised to a certain extent (Geddes 1990).

As a result, three types of resources are analysed: a surface water abstraction (Brakel), a riverbank abstraction (Bergambacht) and a groundwater abstraction (Vessem), located in different (sub) basins (for characteristics and location: see supplementary material). Both the surface water resource and the riverbank resource are fed by water from international river basins that pass densely populated areas and 
areas with agricultural and industrial activity that influence the downstream water quality more or less directly. For a groundwater resource, activities that are situated within the boundaries of a catchment area may cause contamination which could, at some stage, impose a risk of deteriorating groundwater quality. Depending upon the hydrogeological circumstances, the contamination of groundwater resource quality may show up after years, or even decades, and may continue for a very long time after the activity itself has stopped. So a relevant difference between surface water and groundwater resources is the time-scale at which the effects of pressures or remediation measures become apparent.

Multiple authorities at different levels, and drinking water companies, have a duty of care to protect a resource for drinking water production in the Netherlands based upon the Drinking Water Act and a number of more specific legal responsibilities (see Fig. 2). Since 2010, these parties (authorities and stakeholders) have joined forces to set up drinking water protection files (DWPFs) in a voluntary working process to improve water quality (NWO 2010). These documents assess the current and future risks for the quality of the extracted water and enable all parties to take adequate and timely measures; they are also used as a basis for cooperation on resource protection. The planning cycle of the DWPFs is aligned with the timeframe of the WFD.

For our analysis, we used information from the DWPFs, programmes of measures, the relevant river basin management plans (RBMPs), national, provincial and local policy plans, and supporting studies of the water system characteristics and water quality issues. We also collected data from interviews held with all of the parties directly involved in the DWPF process using a standardized questionnaire. The DWPFs summarise all the relevant information required to assess water quality risks and the driving forces in the direct vicinity of the abstraction. Programmes of measures describe the actions agreed upon by the parties involved. River basin management plans characterise the upstream part of the basin and the measures agreed upon within the basin. This information was used to answer the questions in the building blocks 'water system knowledge', 'trade-offs between social objectives' and 'engineering and monitoring' (see Fig. 1) for each of the resources studied. The other elements in the framework were elaborated for each of the resources, based upon the reports of the interviews and supporting studies. The interviews focused on the involvement of stakeholders, roles and responsibilities, the decision making process, the development of measures and observations regarding effectivity so far.

In total 11 representatives from local authorities, water authorities (regional and national), drinking water companies and provinces were interviewed using a standardised questionnaire based upon the information needs of the analytical framework. The national water authority was interviewed in regard to two resources. All the interviews are reported and their contents agreed upon by the interviewees.

\section{Case Study Results: Conditions of Governance Applied to Preserve Drinking Water Resources}

The results of our analysis are described for each of the elements of the analytical framework, jointly if possible and individually if differences are observed between the drinking water resources studied. 


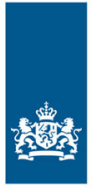

National Institute for Public Health

and the Environment

Ministry of Health, Welfare and Sport

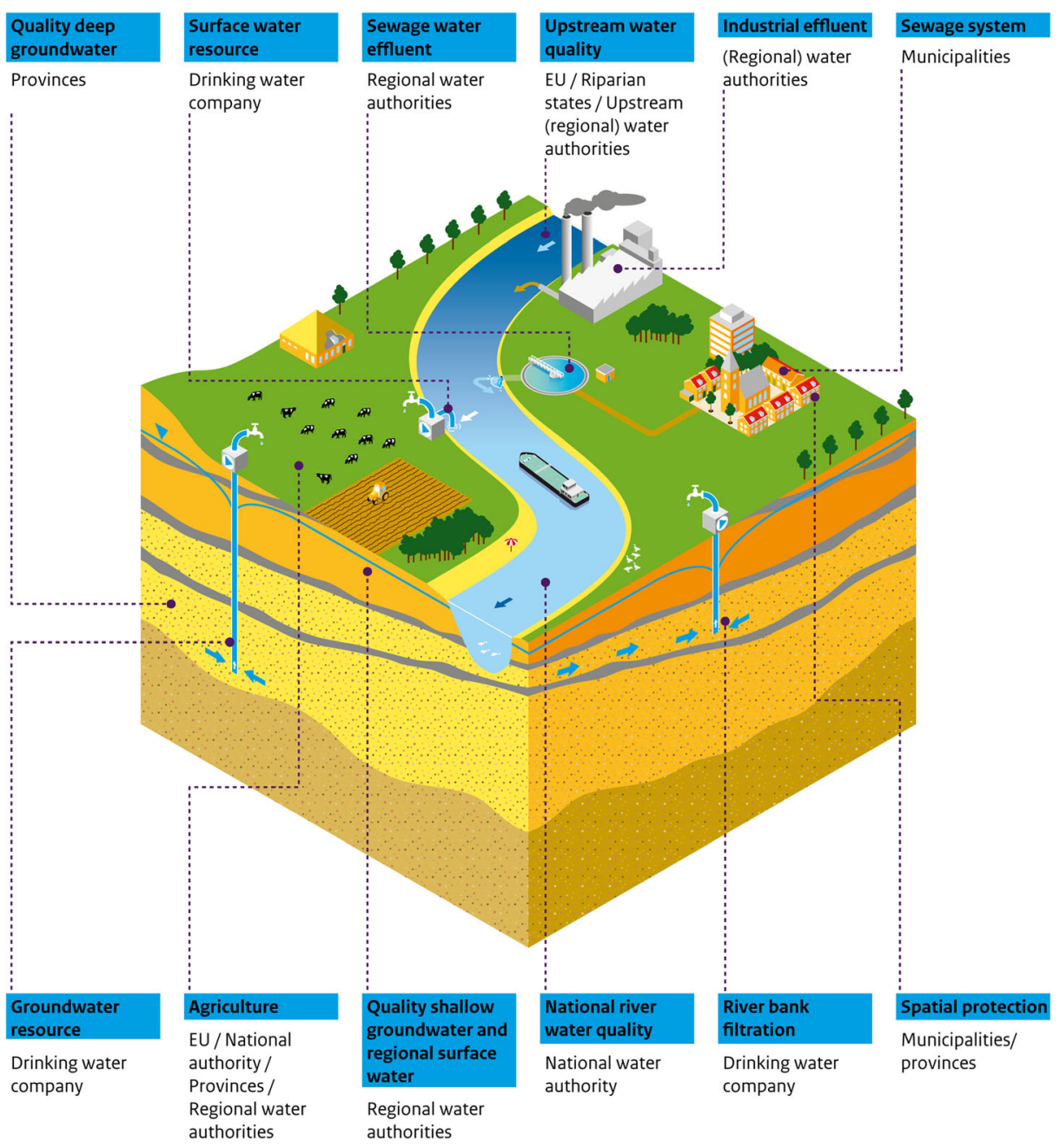

Fig. 2 Schematic view of water system, the types of resources analysed and the actors involved

\subsection{Water System Knowledge}

From the interviews it can be concluded that general knowledge of the water system in the direct vicinity of the resource is sufficiently available, but specific knowledge could be improved on the existence and effects of upstream emissions on downstream surface water 
quality. This is especially relevant for the competent authorities that have options available to them to remediate these risks, but also for the parties involved in the DWPF. This knowledge gap has been identified by the drinking water companies and the national water authority too and they have developed a river water protection file in response which addresses the water quality issues which have an upstream origin. This initiative however, was not based on joint fact-finding with upstream authorities involved or any other interaction and as such, has not contributed to the knowledge of these authorities on the downstream drinking water resource.

Little is known about the effect of measures on the WFD objectives on the groundwater resources because of the complexity of the hydrogeological system and the interactions that occur with measures taken at ground level. This knowledge gap is envisaged to be addressed in the upcoming revision of the DWPFs.

\subsection{Values, Principles and Policy Discourses}

The importance of safe and sustainable drinking water is acknowledged by all parties involved. However, these parties have different views on the importance of other activities that may affect water quality, like agriculture or industry and the division of the costs of pollution. Additionally, interaction between the parties involved is influenced by societal trends and policy developments like decentralisation, deregulation, decreasing government involvement, the demand for strict management and division of responsibilities and the growing value attached to generating consensus (Driessen and Van Rijswick 2011). For the resources analysed, the parties involved seem to limit their contribution to the legal responsibilities they have. A sense of 'ownership' is mainly demonstrated by the drinking water company and the process coordinator (province or water authority depending upon the type of resource). The delayed response of groundwater systems to both polluting activities and quality improving measures at the land surface, makes it more difficult to create a 'sense of urgency' when addressing groundwater issues with parties that do not have a direct interest in, or hold primary responsibility for, the quality of the resource.

\subsection{Stakeholder Involvement}

Competent authorities within the protection zone, and the drinking water company, are involved in setting up the DWPF; other parties like farmers, are involved in the realisation of the measures. Upstream authorities and stakeholders that contribute to the downstream water quality are not yet involved. In addition, some issues can only effectively be addressed at a national or European scale, such as the regulation of emerging substances. As the national authority is not directly involved in the governance process of the individual DWPFs, it is the process coordinator that puts these issues on the agenda of the national authority. The Dutch Drinking Water Policy Paper (IenM 2014) and consequently the RBMPs for the WFD are used as platforms to accommodate this. The process coordinator, however, does not have any means of managing this process of agenda setting. This ineffective connectivity, is identified as a gap in the governance approach by parties involved in the DWPF themselves, but it is yet unclear how this gap could be bridged effectively.

The consumers of drinking water are not directly involved in the protection of resources, although actions are planned for public awareness-raising. Initiatives like the Right2Waterinitiative (http://www.right2water.eu/) show that the general public believes it important to 
have healthy drinking water, but their potential force is rarely used to raise political urgency about the preservation of drinking water resources.

\subsection{Trade-Offs between Societal Objectives: Service Level Agreements}

Most measures agreed upon were qualified by the interviewees as 'low hanging fruit' that can be realised by the parties involved themselves and fit within existing financial plans and formal competences. They have a particular focus on the prevention of new water quality issues. Activities like agriculture are predominantly regulated by general rules. The Dutch political choice that the WFD implementation should not lead to additional costs for the agricultural sector (Parliamentary Papers 2002, 27,625 Water Policy, Amendment Van der Vlies No. 92), resulted in some vulnerable areas, in a situation where the existing general rules on the use of manure and pesticides are insufficient to meet the WFD objectives (Freriks et al. 2016).

The authorities interviewed, consider the commitment of the drinking water company in realising voluntary measures to be an important catalyst for action of other parties, including their own organization.

\subsection{Responsibility, Authority and Means}

A draft programme of measures was agreed upon by the parties involved. The actual decisionmaking on the measures took place within the separate organisations, where different interests are involved as well. This two-step process of decision making, created some distance to the other parties involved in the programme of measures.

For additional regulation, e.g. on the use of manure or pesticides, interaction with the national authority is necessary. This two-sided interaction between national policy and regional practice could be strengthened to the benefit of the water quality objectives. The interviewees indicated that having a joint approach and shared financing mechanisms were important conditions for realising voluntary measures.

The role of process coordinator is covered well by the provinces and the national water authority. As yet, however, it is unclear how cross-scale water quality issues especially from upstream non-point source pollution, should be addressed and which would be the most suitable competent authority to address this. To date, there are no mutual agreements in place to sort out these cross-scale interactions, although very recently a national protocol for licensing has been set up to assess the effects of an upstream spill on downstream resources.

\subsection{Regulations and Agreements}

The protection of drinking water resources is regulated by a complex legal framework containing laws whose objectives do not always coincide with the objectives of the Dutch Drinking Water Act. As a consequence, there can be different perspectives on the necessity of taking measures, for instance, on the necessity of cleaning up point source soil pollutions from the past or the necessity to take actions upon emerging substances such as pharmaceuticals or industrial chemicals. The Drinking Water Act introduced, in Article 2, a 'duty of care' regarding the drinking water supply and the qualification: an 'imperative reason of overriding public interest'. Both elements reach out to all authorities. The qualification refers to a public interest that, in principle, ought to carry more weight than other conflicting interests and that should be accounted for when balancing different interests e.g. in spatial planning processes. 
As yet, the implications of this qualification seem unclear to the parties involved, thus leaving its potential benefits unused.

The policy framework is orientated in a mainly top-down manner at the moment. Bottomup experiences are used for agenda setting on a national level but no explicit mutual agreements on measures that are related to water quality issues are currently available. This makes it difficult to manage progress on issues raised. Experiences with the DWPF show that these bottom-up, and cross-scale interactions with explicit mutual agreements, are additional necessary conditions if water quality objectives are to be achieved. The river basin approach, as introduced by the WFD, could be used in such a way, but this isn't common practice yet.

\subsection{Financing Water Management}

The protection of drinking water resources is financed in different ways by the different authorities involved and varies from financing by general public means to financing by specific taxes for industrial spills. The 'polluter pays'-principle is only partly implemented in the financial arrangements. No explicit societal cost-benefit analysis is made of the selection of measures. Measures so far, fit within existing plans of the parties involved.

\subsection{Engineering and Monitoring}

The programmes of measures for all the resources analysed focused mainly on measures which have obvious positive effects, but the information on the expected and the actual effect of measures on water quality is lacking. Monitoring systems to check the effectiveness of measures in the programme have not yet been designed. To date, the extent to which a measure has been realized has been assessed by evaluating its progress (output) and not its effect on water quality (outcome). As the effects of measures are not always clear in advance, it is particularly important to monitor them, to be able to adapt measures accordingly, so as to realise the objectives of the WFD. The complexity of the water system and the interaction with the driving forces of water quality makes monitoring outcomes a challenge that needs further study.

\subsection{Enforcement}

The use of enforcement differs for the resources analysed. Monitoring of the abstracted water from the surface water resource has initiated multiple enforcement actions because of illegal spills in the adjacent polder. There is no active enforcement on upstream activities related to the specific drinking water objectives downstream. In the groundwater protection zone of the riverbank resource, both the drinking water company and the province check new initiatives that might impose a risk to the resource. In regard to the groundwater resource, interviewees indicated that it was rather unclear how enforcement took place in the area and by whom.

\subsection{Conflict Prevention and Resolution}

The interviewees indicated that participating in the preparation of the DWPF had increased cooperation between the parties involved. The parties involved at the groundwater resource have agreements on conflict resolution but at the other resources analysed no such agreements 
have been made. Drinking water companies make limited use of the opportunities provided by legal procedures.

\section{Discussion on Case Study Results: Governance Conditions for Improving Water Quality}

The results of our case study and data from a national review of the DWPFs (Wuijts et al. 2014, Van den Brink and Wuijts, 2016) have been used to analyse our theoretical proposition, that to address water quality issues effectively, a governance approach should be linked up with the water system characteristics, the drivers of water quality issues and with the authorities which have the means to adopt adequate measures and monitor the progress of said measures. So, in terms of the analytical framework (see Fig. 1), we are testing the importance of connectivity between the elements of content (building blocks: water system knowledge, values and principles), organisation (especially building blocks: 'stakeholder involvement', 'authority and means', 'regulations and agreements') and implementation (especially building blocks: 'engineering and monitoring', 'enforcement').

The current DWPFs focus on the direct vicinity of the abstraction, the protection zone. For riverbank and surface water resources it is, however, necessary to assess the upstream basin, as well as the direct vicinity of the abstraction, to identify which activities and water system conditions are affecting water quality downstream. At this moment, the majority of substances imposing a risk for drinking water production at these resources (e.g. pharmaceuticals and industrial substances), originate from upstream sources. At the same time upstream regional authorities and higher levels of government have a responsibility and different sectors have opportunities to take measures that could affect downstream water quality, yet not all of them are directly involved because of the complex nature of the process. In order to achieve most of the water quality objectives it is necessary to somehow involve these authorities and sectors, e.g. on the use of manure, pesticides and pharmaceuticals (Freriks et al. 2016). As a consequence, the measures planned contribute to the prevention of acute risks in the direct vicinity of the abstraction but do little to improve the water quality issues that are caused by activities further upstream and as such support the proposition of this study.

The limited connectivity between content, organisation and implementation of the governance processes applied so far, can be recognised in general at other resources in the Netherlands as well (Wuijts et al. 2014).

As a result, three interrelated conditions of governance stand out as key elements for improving water quality: enhancing connectivity, joint fact finding and explicit decisionmaking and finally, monitoring of effects on water quality. These conditions will be discussed in the following part of this section.

The first condition, enhancing connectivity between different hydrological scales and institutional levels and sectors involved at these scales seems to be a dominant condition throughout the governance process. The governance process of setting up the DWPFs has demonstrated the importance of this condition but has also flagged up the need for further evolution of this process in the current DWPFs. The WFD implementation process is designed to serve as a platform for cross-scale and multi-level interaction (river basin approach) but could be improved with interaction mechanisms based on mutual explicit agreements on outcomes. Cash et al. (2006) conclude from literature that systems that address these scale issues consciously tend to be more successful in assessing problems and finding solutions. 
Various publications demonstrate that synchronisation of interactions between levels, more often result in actions being taken as they were intended to be by the levels involved (Gilissen et al. 2016; Leventon 2015; Van Popering-Verkerk and Van Buuren 2016). For some issues, e.g. emerging substances, interaction with the national authority is necessary. To serve water quality improvement this interaction should be managed explicitly on objectives and mutual agreements (Orr et al. 2015).

The second key condition, the importance of joint fact-finding, raises questions about who should be involved and how to reach out to those not directly involved. Determining who should be involved should be based upon the characteristics of the water system (where does the water come from), the drivers determining water quality and the actors who have the authority and the means to take measures. How to involve the relevant parties further upstream or at other institutional levels is a question that is more difficult to answer. Interviewees indicated that the joint fact-finding and the resulting shared perception of risk was an important benefit of the governance approach. The resulting perception of risk, however, is not necessarily shared by the (upstream or national) parties not involved. This especially holds for water quality issues that are not yet regulated as is the case for emerging substances such as pharmaceuticals. Any joint fact-finding process, therefore, that has not involved all relevant parties may well be flawed (Jetoo et al. 2014; OECD 2014; Runhaar et al. 2006; Van Buuren and Koppenjan 2014). As the OECD (2014) explains, a party has to have a specific interest at stake if it is to become engaged.

The third condition is the process of decision-making and the monitoring of the effects of measures. At this moment a tiered approach is used: agreement on a draft programme of measures by the parties involved and then the actual decision-making within the separate organisations, where different interests are also involved. This second step created some distance between the parties involved, which was a less fruitful situation for initiating follow-up joint actions. The interviewees indicated that having a joint approach and financing mechanisms were important conditions in realising voluntary measures.

To date, the effect of measures is monitored on output (progress of measures undertaken) and not on outcome (progress of water quality improvement) or not monitored at all. Monitoring on outcome could help parties understand whether the objectives are being realised and/or whether additional action is needed, thus making the approach more adaptive towards the objectives (Rijke et al. 2012). In the programmes of measures, agreements on disagreements are only incorporated in a very limited way, thus leaving little opportunity to tackle a party who doesn't follow up on the measures agreed upon.

\section{Conclusions: Governance Conditions for Water Quality Improvement}

In this study we have analysed empirical data on what conditions of governance contribute to the realisation of water quality objectives. To date, empirical studies on how conditions of governance could contribute to improve specific water quality issues are scarce. This understanding however, is important to identify relevant interventions for both policy makers and other stakeholders involved. Although our data was limited to the Netherlands and a limited number of resources, three widely-applied types of resources have been analysed, a surface water, a river bank filtration and a groundwater resource, and compared to the 200 other resources in the Netherlands. The water quality challenges at these resources, nitrates, pesticides, industrial chemicals and pharmaceuticals, can be seen in other European countries as 
well. Complying with the objectives set by the WFD initiates similar challenges in these countries, so insights gained into the conditions of governance to improve water quality are, therefore, of relevance in an international arena.

We conclude that the results of our analysis support our initial theoretical proposition that to address water quality issues effectively, a governance approach should be linked up with the water system characteristics, the drivers of water quality issues and with the authorities which have the means to adopt adequate measures and monitor the progress of said measures. The analysis demonstrates the importance to enhance connectivity between institutional levels and different regions based upon the characteristics of the water system and driving forces for water quality and thus involve the actors that have the authority and the means to take effective measures. The other important conditions of governance approaches for water quality improvement which were identified are the use of joint fact-finding to establish a shared perception of the risks and the use of explicit decision-making and finally the monitoring on outcome (water quality improvement) rather than output. Since this analysis is limited to one country and a limited number of drinking water resources, it would be very relevant to assess whether these findings can be recognized in other countries with different institutional settings as well.

The analytical framework used for this analysis (Van Rijswick et al. 2014) was applicable to test our proposition as it covers a wide range of elements relevant to water governance. However, since the questions formulated for each of the building blocks are rather generic, the framework was refined with indicators from the WSP approach (WHO 2009) to create more focus on water quality issues, especially for the building blocks 'water system knowledge' and 'engineering and monitoring'. This refinement served well to assess the building block 'water system knowledge', but the building block 'engineering and monitoring' could benefit from further targeting in order to assess the potential effect of planned measures and their follow up. The question that needs to be addressed is whether, and to what extent, this further targeting of the framework is applicable to other water functions like nature preservation or urban water usages which also have specific quality challenges or whether each water function sets its own specific demands on the conditions for governance.

Acknowledgements We would like to thank Monique van der Aa, Cors van den Brink, Wilko Verweij, Jeroen Devilee and Sandra Boekhold and the anonymous reviewers for their valuable comments on earlier versions of this paper.

\section{Compliance with Ethical Standards}

Conflict of Interest The authors declare that they have no conflict of interest.

Open Access This article is distributed under the terms of the Creative Commons Attribution 4.0 International License (http://creativecommons.org/licenses/by/4.0/), which permits unrestricted use, distribution, and reproduction in any medium, provided you give appropriate credit to the original author(s) and the source, provide a link to the Creative Commons license, and indicate if changes were made.

\section{References}

Adger W, Arnella N, Tompkins E (2005) Successful adaptation to climate change across scales. Glob Environ Chang 15:10 
Blackstock K, Waylen K, Dunglinson J, Marshall K (2012) Linking process to outcomes — internal and external criteria for a stakeholder involvement in River Basin management planning. Ecol Econ 77:10

Boeuf B, Fritsch O (2016) Studying the implementation of the water framework directive in Europe: a metaanalysis of 89 journal articles. Ecol Soc 21:19

Brack W, Altenburger R, Schüürmann G, Krauss M, López Herráez D, van Gils J, Slobodnik J, Munthe J, Gawlik BM, van Wezel A, Schriks M, Hollender J, Tollefsen KE, Mekenyan O, Dimitrov S, Bunke D, Cousins I, Posthuma L, van den Brink PJ, López de Alda M, Barceló D, Faust M, Kortenkamp A, Scrimshaw M, Ignatova S, Engelen G, Massmann G, Lemkine G, Teodorovic I, Walz KH, Dulio V, Jonker MTO, Jäger F, Chipman K, Falciani F, Liska I, Rooke D, Zhang X, Hollert H, Vrana B, Hilscherova K, Kramer K, Neumann S, Hammerbacher R, Backhaus T, Mack J, Segner H, Escher B, de Aragão Umbuzeiro G (2015) The SOLUTIONS project: challenges and responses for present and future emerging pollutants in land and water resources management. Sci Total Environ 503-504:10-31. https://oi. org/10.1016/j.scitotenv.2014.05.143

Bressers JTA, Boer CL, Lordkipanidze M, Özerol G, Vinke-de Kruijf J, Farusho C, Browne A et al(2013). Water governance assessment tool: with an elaboration for drought resilience. INTERREG IVbDROP project. https://research.utwente.nl/en/publications/water-governance-assessment-tool-with-anelaboration-fordrought

Bucknall J (2006) Good governance for good water management. Environment matters - The World Bank Group. https://siteresources.worldbank.org/INTENVMAT/64199955-1162240805462/21127276 /8GoodGovernance.pdf

Cash DW, Adger W, Berkes F, Garden P, Lebel L, Olsson P, Pritchard L, Young O (2006) Scale and cross-scale dynamics: governance and information in a multilevel world. Ecol Soc 11:2-8

Dalhuisen J, Rodenburg C, De Groot H, Nijkamp P (2003) Sustainable water management policy: lessons from Amsterdam. Eur Plan Stud 11:19

Den Uyl R, Driessen PPJ (2015) Evaluating governance for sustainable development; insights from experiences in the Dutch fen landscape. J Environ Manag 163:18

Dieperink C, Raadgever G, Driessen PPJ, Smit A, Van Rijswick HFMW (2012) Ecological ambitions and complications in the regional implementation of the water framework directive in the Netherlands. Water Policy 14:14

Driessen PPJ, Van Rijswick HFMW (2011) Normative aspects of climate adaptation policies. Climate Law 2:13. https://doi.org/10.3233/CL-2011-051

EC (2001) European governance - a white paper COM (2001) 428 final

EC (2013) A water blueprint for Europe. Publications Office of the European Union, Luxembourg. https://doi. org $/ 10.2779 / 12145$

Edelenbos J, Bressers N, Scholten P (2013) Water governance as connective capacity. Ashgate Publishing Limited, Farnham

Flindt Jörgensen L, Villhoth K, Refsgaard J (2016) Groundwater management and protection in Denmark: a review of preconditions, advances and challenges. Int J Water Resour Dev 23(6):868-889. https://doi. org/10.1080/07900627.2016.1225569

Freriks A, Keessen A, Korsse D, Van Rijswick H, Bastmeijer K (2016) As far as the own instruments reach: a study on the position of the provincie of North-Brabant and the North-Brabant water authorities in the realization of the water framework objectives, with special attention to the new Dutch environmental act (in Dutch). Utrecht University, University of Tilburg, Utrecht

Geddes B (1990) How the cases you choose affect the answers you get: selection bias in comparative politics. Polit Anal 2:20

Gilissen H, Alexander M, Beyers J, Chmielewski P, Matczak P, Schellenberger T, Suykens C (2016) Bridges over troubled waters - an interdisciplinary framework for evaluating the interconnectedness within fragmented flood risk management systems. Journal of Water Law 25:15

Havekes H, Hofstra M, Van der Kerk A, Teeuwen B (2013) Building blocks for good water governance. Water Governance Centre, the Netherlands

Houtman C (2010) Emerging contaminants in surface waters and their relevance for the production of drinking water in Europe. J Inegr Environ Sci 7:25

Howard G, Schmoll O (2006) Water safety plans: risk management approaches for the delivery of safe drinking water from groundwater sources. In: Schmoll O, Howard G, Chilton J, Chorus I (eds) Protecting groundwater for health: managing the quality of drinking-water sources. IWA Publishing, London, pp 431-464

Howarth W (2017) Water pollution and water quality - shifting regulatory paradigms. In: Howarth W, RieuClarke A, Allen A, Hendry S (eds) Handbook on water law and policy, Routlegde, New York

IenM (2014) Drinking water policy paper (in Dutch). Ministry of Infrastructure and the Environment. IenM, The Hague. https://www.rijksoverheid.nl/documenten/rapporten/2014/04/25/beleidsnota-drinkwater-schoondrinkwatervoor-nu-en-later 
Jetoo S, Thorn A, Friedman K, Gosman S, Krantzberg G (2014) Governance and geopolitics of drivers of change in the Great Lakes-St. Lawrence basin. J Great Lakes Res 1:11

Kayser G, Amjad U, Dalcanale F, Bartram J, Bentley M (2015) Drinking water quality governance: a comparative case study of Brazil, Ecuador and Malawi. Environ Sci Pol 48:10

Koop S, Van Leeuwen C (2016) Assessment of the sustainability of water resources management: a critical review of the city blueprint approach. Water Resour Manag 29(15):22-5670. https://doi.org/10.1007 /s11269-015-1139-Z

Lange P, Driessen P, Sauer A, Bornemann B, Burger P (2013) Governing towards sustainability: conceptualizing modes of governance. J Environ Policy Plan 15:25

Lee M (2009) Law and governance of water protection policy. In: Scott J (ed) EU environmental governance. Oxford University Press, Oxford. https://doi.org/10.1093/acprof:oso/9780199565177.003.0002

Leventon J (2015) Explaining implementation deficits through multi-level governance in the EU's new member states: EU limits for arsenic in drinking water in Hungary. J Environ Plan Manag 58:17

Metz F, Ingold K (2014) Sustainable wastewater management: is it possible to regulate micropollution in the future by learning from the past? A policy analysis. Sustainability $6: 19$

Newig J, Fritsch O (2009) Environmental governance: participatory, multi-level - and effective? Environmental Policy and Governance 19:18

NWO (2010) National agreements on the implementation of drinking water protection files for the public drinking water supply (in Dutch). Memo for the Dutch National Water Committee (NWO)

OECD (2014) Water governance in the Netherlands: fit for the future? OECD, Paris. https://doi.org/10.1787 /9789264102637-en

OECD (2015) OECD principles on water governance (Daegu declaration). OECD, Paris

Orr C, Adamowski J, Medema W, Milot N (2015) A multi-level perspective on the legitimacy of collaborative water governance in Québec. Can Water Res J 41(3):353-371. https://doi.org/10.1080 $/ 07011784.2015 .1110502$

Overheu N, Troldborg, MB, Tuxen, NA, Flyvbjerg, JC, Østergaard, HC, Jensen, CBC, Binning, PJB, Bjerg, PLB (2011) Risk-based prioritisation of point sources through assessment of the impact on a water supply. IAHSAISH Publication 342:4

Pahl-Wostl C, Lebel L, Knieper C, Nikitina E (2012) From applying panaceas to mastering complexity: towards adaptive water governance in river basins. Environ Sci Pol 23:11

Plambeck E (2015) Paradoxes of the EU regulatory framework in water management: developing an assessment framework to put the governance approach to the test. The Journal of Water Law 24:9

Quevauviller P (2010) Is IWRM achievable in practice? Attempts to break disciplinary and sectoral walls through a science-policy interfacing framework in the context of the EU water framework directive. Irrig Drain Syst 24:13

Rijke J, Brown R, Zevenbergen C, Ashley R, Farrelly M, Morison P, Van Herk S (2012) Fit-for-purpose governance: a framework to make adaptive governance operational. Environ Sci Pol 22:12

Runhaar H, Dieperink C, Driessen P (2006) Policy analysis for sustainable development. The toolbox for the environmental social scientist international. Journal of sustainability in. High Educ 6(1):23-56. https://oi. org/10.1108/14676370610639236

Salinas A (2015) Integrated water resources management under a new global scenario. Water Sci Technol Water Supply 15:9

Scott J, Trubek D (2002) Mind the gap: law and new approaches to governance in the European Union. Eur Law J 8:18

Six S, Diez T, Van Limbergen B, Keustermans L (2015) Development of a risk-based approach for a better protection of drinking water catchments in Flanders (Belgium). Water Sci Technol Water Supply 15:7. https://doi.org/10.2166/ws.2015.029

Ter Laak T, Van der Aa N, Houtman C, Stoks P, Van Wezel A (2010) Relating environmental concentrations of pharmaceuticals to consumption: a mass balance approach for the river Rhine. Environ Int 36:7

Van Buuren MW, Koppenjan JFM (2014) Policy analysis in networks: the battle of analysis and the potentials of joint fact-finding. In: Van Nispen F, Scholten P (eds) Policy analysis in the Netherlands. Policy Press, Bristol pp 33-48

Van den Brink C, Wuijts S (2016) Towards an effective protection of groundwater resources: putting policy into practice with the drinking water protection file. Water Policy 18:19

Van der Aa NGFM et al (2013) Risk assessment for drugs of abuse in the Dutch watercycle. Water Res 47:20

Van Holten S, Van Rijswick H (2014) The consequences of a governance approach in European environmental directives for flexibility, effectiveness and legitimacy. EU environmental legislation - Legal perspectives on regulatory strategies. Edward Elgar Publishing, Cheltenham

Van Popering-Verkerk J, Van Buuren MW (2016) Decision-making patterns in multilevel governance: the contribution of informal and procedural interactions to significant multilevel decisions. Public Management Review 18:21 
Van Rijswick H (2008) Moving water and the law - on the distribution of water rights and water duties within river basins in European and Dutch water law. Europa Law Publishing, Groningen

Van Rijswick H, Edelenbos J, Hellegers P, Kok M, Kuks S (2014) Ten building blocks for sustainable water governance: an integrated method to assess the governance of water. Water Int 39(5):725-742. https://oi. org/10.1080/02508060.2014.951828

Warner J, Van Buuren A (2016) Reframing long-term controversies in transboundary river management. The intermediate role of puzzling and powering in tackling wicked problems. Futures 76:12

WHO (2009) Water safety plan manual (WSP manual) Step-by-step risk management for drinking water suppliers. World Health Organization, Geneva. http://apps.who.int/iris/bitstream/10665/75141/1/9789241562638_eng. pdf

WHO (2016) Drinking-water; Fact sheet. http://www.who.int/mediacentre/factsheets/fs391/en/. Accessed 21 Jan 2017

Wuijts S, Bogte J, Dik H, Verweij W, Van der Aa N (2014) Review of drinking water protection files (in Dutch, abstract in English) vol 270005001. RIVM, the Netherlands 